\title{
Mathematical Modelling and Identification of a Quadrotor
}

César A. Cárdenas R., Carlos Andrés Collazos Morales, Juan P. Ospina, Joaquín F. Sánchez, Claudia Caro-Ruiz, Víctor Hugo Grisales, Paola Ariza-Colpas, Emiro De-la-Hoz-Franco, Ramón E. R. González

\begin{abstract}
Motivated by the important growth of VTOL vehicles research such as quadrotors and to a small extent autonomous flight, a quadrotor dynamical model is presented in this work. The purpose of this study is to get a better understanding of its flight dynamics. It is an underactuated system. So, a simplified and clear model is needed to implement controllers on these kind of unmanned aerial systems. In addition, a computational tool is used for validation purposes. For future works embedded or intelligent control systems can be developed to control them. Gyroscopic and some aerodynamics effects are neglected.
\end{abstract}

Keywords: Quadrotor, VTOL, Flight dynamics, UAV 